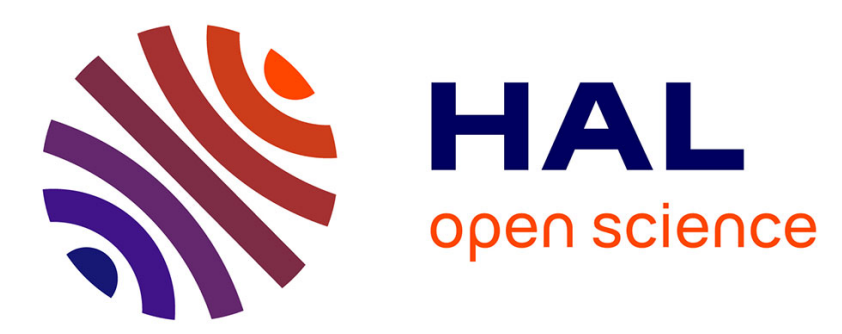

\title{
Experimental study of recombining nitrogen plasmas: I. Vibronic population distributions and nonequilibrium molecular radiation
}

Augustin Tibère-Inglesse, Sean Mcguire, Pierre Mariotto, Christophe O. Laux

\section{- To cite this version:}

Augustin Tibère-Inglesse, Sean Mcguire, Pierre Mariotto, Christophe O. Laux. Experimental study of recombining nitrogen plasmas: I. Vibronic population distributions and nonequilibrium molecular radiation. Plasma Sources Science and Technology, 2019, 28 (7), pp.075018. 10.1088/1361-6595/ab2cc4 . hal-02494227

\section{HAL Id: hal-02494227 \\ https://hal.science/hal-02494227}

Submitted on 28 Feb 2020

HAL is a multi-disciplinary open access archive for the deposit and dissemination of scientific research documents, whether they are published or not. The documents may come from teaching and research institutions in France or abroad, or from public or private research centers.
L'archive ouverte pluridisciplinaire $\mathbf{H A L}$, est destinée au dépôt et à la diffusion de documents scientifiques de niveau recherche, publiés ou non, émanant des établissements d'enseignement et de recherche français ou étrangers, des laboratoires publics ou privés. 


\title{
Experimental study of recombining nitrogen plasmas. Part I: Vibronic population distributions and nonequilibrium molecular radiation
}

\author{
Augustin C. Tibère-Inglesse ${ }^{1,2}$, Sean D. McGuire ${ }^{2}$, Pierre Mariotto ${ }^{2}$ and Christophe O. Laux ${ }^{2}$ \\ ${ }^{1}$ ArianeGroup, 66 Route de Verneuil, 78130 Les Mureaux \\ ${ }^{2}$ Laboratoire EM2C, CNRS UPR288, CentraleSupélec, Université Paris-Saclay, 10 rue Joliot-Curie, \\ 91190 Gif-sur-Yvette, France
}

\begin{abstract}
We present optical emission spectroscopy measurements in recombining nitrogen plasma flows at atmospheric pressure. An inductively coupled plasma torch is used to create an equilibrium plasma, which is then forced to recombine by flowing through a water-cooled tube. For certain conditions, the plasma is forced out of chemical equilibrium. The emission of $N_{2}\left(B^{3} \Pi_{g}\right), N_{2}\left(C^{3} \Pi_{u}\right)$ and $N_{2}^{+}\left(B^{2} \Sigma_{u}^{+}\right)$ is studied to measure the nonequilibrium vibrational density distributions within these electronic states. These densities are found to be highly overpopulated in comparison with their corresponding equilibrium values, which is consistent with previous results in recombining flows. The measured densities are also compared with the predictions of a 2-temperature model. This 2-temperature model underpredicts the measured densities but is closer to the measured distributions than the equilibrium densities. The total measured radiation is approximately 100,000 times stronger than the corresponding equilibrium radiation. The 2-T model estimate of this radiation is much closer yet still underestimates by a factor of 10 the measured radiation. These data are intended as a new dataset to test the recombining plasma models used to simulate afterbody flows during atmospheric reentry.
\end{abstract}

\section{Introduction}

In recent years, there has been increased interest in manned Mars return missions [1]. There are numerous challenges to achieving such a mission. One such challenge is the reentry into the Earth atmosphere on the return voyage [2]. During reentry, the capsule enters the atmosphere at velocities above $10 \mathrm{~km} / \mathrm{s}$ [3]. At these high velocities, the shock-heated plasma layer formed around the vehicle can result in a radiative heat flux higher than the convective flux [4] [5]. The radiation on the forebody has been the focus of much research [6] [7] [8] [9] and is relatively well modeled. However, uncertainties on the afterbody radiative heat flux can still be as high as $200 \%$ [3] [4]. One of the reasons for this uncertainty is the rapid expansion into the afterbody region which forces recombination and a subsequent departure from thermochemical equilibrium conditions. A fundamental study of recombination kinetics is therefore necessary to correctly predict the degree of nonequilibrium of recombining plasmas and the resulting radiation. Recent work has focused on the kinetics and radiation of recombining plasma flows, both experimentally and numerically: see for example Refs. [10] [11] [12]. This paper focuses on nitrogen recombination kinetics.

In a previous paper [13], we presented experiments for recombining nitrogen and air plasmas flows using the plasma torch facility at the EM2C laboratory. The plasma torch provides an equilibrium plasma at atmospheric pressure. The plasma then flows through a water-cooled tube at relatively high velocity $(\sim 1 \mathrm{~km} / \mathrm{s})$. The plasma exits the tube in a state of chemical nonequilibrium. The resulting radiation at the exit of the tube was found to be up to 100,000 times higher than if the plasma were in equilibrium at the measured gas temperature determined via Raman spectroscopy measurements of the $\mathrm{N}_{2}\left(\mathrm{X}^{1} \Sigma_{\mathrm{g}}^{+}\right)$ ground state. Finally, CFD codes failed to predict any of the measured temperatures under any of the experimental conditions - even those where the plasma remained in equilibrium [13]. This same discrepancy between measurements and CFD codes was previously observed by other authors [14] [15]. 
These measurements therefore raised questions about the ability of the CFD codes to predict this temperature drop, the level of nonequilibrium, and the resulting radiation.

In this paper, we analyze the radiation of the plasma over the range $250-900 \mathrm{~nm}$ to obtain the absolute densities of vibrational states of $\mathrm{N}_{2}\left(\mathrm{~B}^{3} \Pi_{\mathrm{g}}\right), \mathrm{N}_{2}\left(\mathrm{C}^{3} \Pi_{\mathrm{u}}\right)$ and $\mathrm{N}_{2}^{+}\left(\mathrm{B}^{2} \Sigma_{\mathrm{u}}^{+}\right)$. This was previously done only for the $\mathrm{N}_{2}$ first positive system [13] up to $800 \mathrm{~nm}$. We study two experimental conditions corresponding to two total mass flow rates. The mass flow rate has a significant impact on the degree of nonequilibrium observed in the plasma. In section 1, we present the experimental setup and conditions. The measured nonequilibrium radiation coming from the plasma is presented in section 2 . The emission spectra are analyzed to provide information on the absolute densities of the vibrational levels of various electronic states of $\mathrm{N}_{2}$ and $\mathrm{N}_{2}{ }^{+}$and on the total radiative heat flux of the recombining plasma flows.

\section{I) Experimental setup}

The plasma torch facility is a TAFA Model 66 inductively coupled plasma (ICP) torch powered by a 120-kVA radio-frequency (4 MHz) LEPEL Model T-50-3 power supply. The power supply can generate a maximum of $12 \mathrm{kV} \mathrm{DC}$ and $7.5 \mathrm{~A}$ to the oscillator plates. Details of the plasma torch facility are provided in previous publications [12] [16] [17]. The plasma produced within the torch exits through a $1-\mathrm{cm}$ diameter nozzle at a speed between 400 and $800 \mathrm{~m} / \mathrm{s}$. The plasmas studied here are comprised of 1.2 or $1.9 \mathrm{~g} / \mathrm{s}$ of $\mathrm{N}_{2}$ or air, premixed with $1.5 \mathrm{~g} / \mathrm{s}$ of argon to provide stable operating conditions for the torch. A water-cooled tube made of brass is mounted on top of the plasma torch exit nozzle. The length of the tube is either 10 or $15 \mathrm{~cm}$. Emission and Raman measurements are performed at the entrance and exit of the modular tube. The plasma is forced to recombine by imposing rapid cooling via the cold wall (maintained at approximately $300 \mathrm{~K}$ ). This setup is therefore intended as a simplified experimental model of a recombining flow in atmospheric reentry. Details of the experimental setup are presented in figure 1.

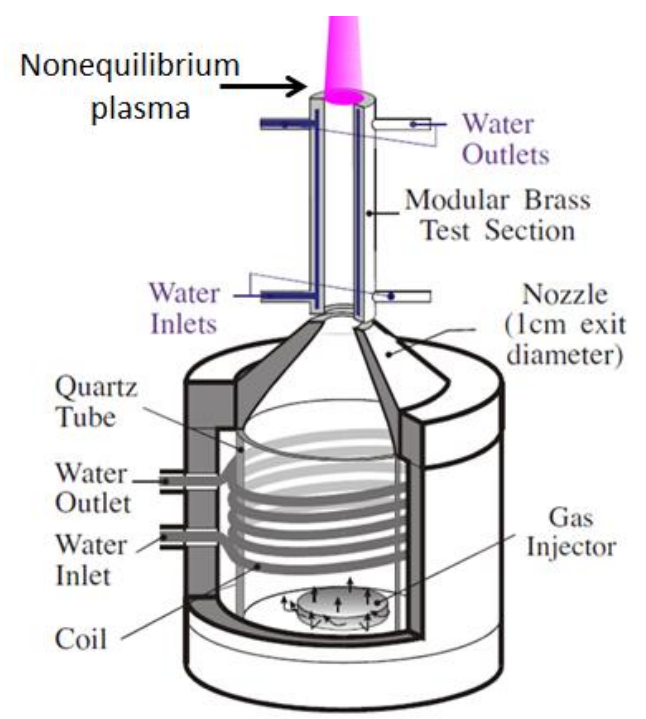

Figure 1: Water-cooled test-section mounted on top of the plasma torch exit nozzle

Optical emission spectroscopy was performed for several experimental conditions with the setup presented in Figure 2. The spectrometer is an Acton Instrument 2500i of 50-cm focal length with a 600 $\mathrm{gr} / \mathrm{mm}$ grating blazed at $300 \mathrm{~nm}$. We measured spectra from 250 to $900 \mathrm{~nm}$ to capture the emission bands of the first and second positive systems of $\mathrm{N}_{2}$, and of the first negative system of $\mathrm{N}_{2}{ }^{+}$. The emission spectra are calibrated from pixel counts to absolute intensities using an Optronics Laboratories tungsten lamp (model OL550) between 400 and $900 \mathrm{~nm}$, and a calibrated argon mini-arc for wavelengths below $400 \mathrm{~nm}$. Spectra are taken each $0.5 \mathrm{~mm}$ along the line of sight and are Abel-inverted to get spatially 
resolved local plasma emission. The three different mixtures considered in this study are summarized in Table 1 .

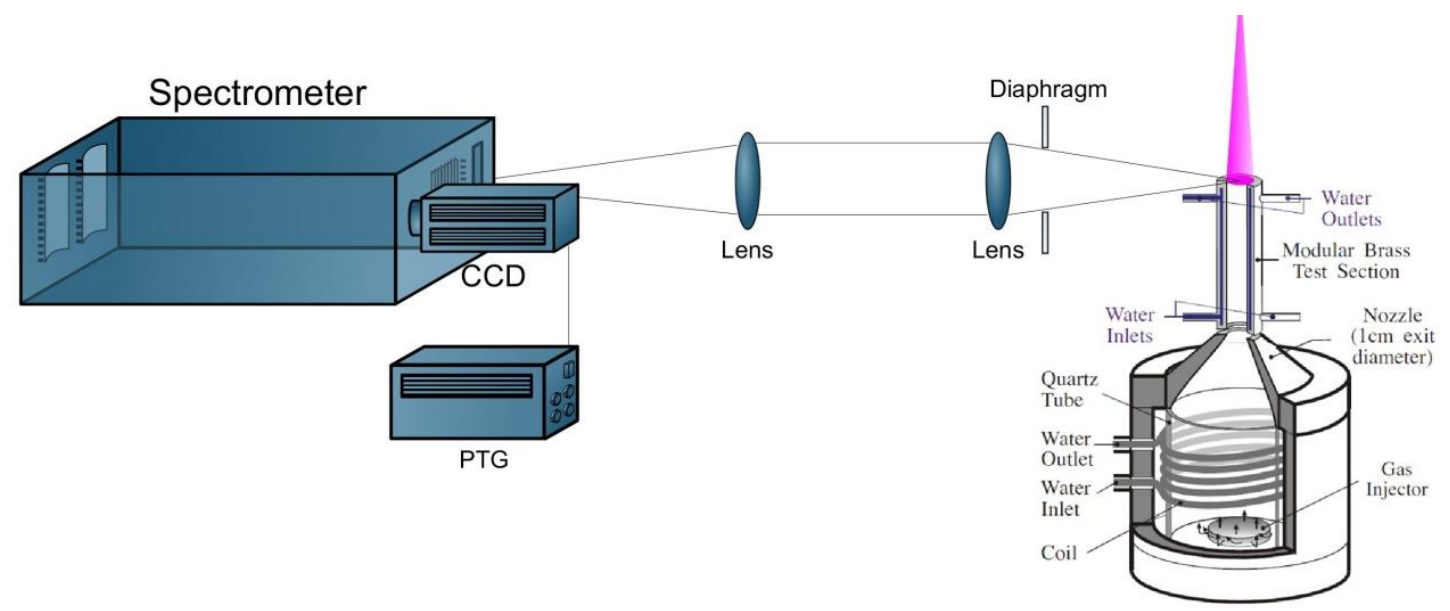

Figure 2: Experimental setup for optical emission spectroscopy (here at the tube exit)

Table 1: Mass flow rates and conditions for the different cases studied. The chemical conditions are taken from Ref [13].

\begin{tabular}{|l|l|l|l|l|}
\hline & Mass flow rate & $\begin{array}{l}\text { Reynolds number } \\
\text { based on the tube } \\
\text { diameter }(1 \mathrm{~cm})\end{array}$ & $\begin{array}{l}\text { Conditions } \\
\text { at tube inlet }\end{array}$ & Conditions at tube exit \\
\hline Air/Ar & $\begin{array}{l}\dot{m}_{\text {Air }}= \\
1.9 \mathrm{~g} / \mathrm{s} \\
\dot{m}_{A r}=1.5 \mathrm{~g} / \mathrm{s}\end{array}$ & $\sim 3600$ (turbulent) & LTE & LTE \\
\hline $\begin{array}{l}\mathrm{N}_{2} / \text { Ar Low } \\
\text { Flowrate (LF) }\end{array}$ & $\begin{array}{l}\dot{m}_{N_{2}}=1.2 \mathrm{~g} / \mathrm{s} \\
\dot{m}_{A r}=1.5 \mathrm{~g} / \mathrm{s}\end{array}$ & $\begin{array}{l}\sim 2700 \text { (slightly } \\
\text { turbulent) }\end{array}$ & LTE & $\begin{array}{l}\text { Thermal equilibrium, } \\
\text { Chemical nonequilibrium }\end{array}$ \\
\hline $\begin{array}{l}\mathrm{N}_{2} / \text { Ar High } \\
\text { Flowrate (HF) }\end{array}$ & $\begin{array}{l}\dot{m}_{N_{2}}=1.9 \mathrm{~g} / \mathrm{s} \\
\dot{m}_{A r}=1.5 \mathrm{~g} / \mathrm{s}\end{array}$ & $\sim 3600$ (turbulent) & LTE & $\begin{array}{l}\text { Thermal equilibrium, } \\
\text { Chemical nonequilibrium }\end{array}$ \\
\hline
\end{tabular}

\section{II) Nonequilibrium radiation of $\mathrm{N}_{2}(B), \mathbf{N}_{2}(C)$ and $\mathbf{N}_{2}+(B)$}

This section discusses the experimental results for each of the three cases outlined in Table 1.

\section{Air/Ar plasma:}

The test conditions for this test are presented in Table 1 . The inlet gas is air $(1.9 \mathrm{~g} / \mathrm{s})$ premixed with $\operatorname{argon}(1.5 \mathrm{~g} / \mathrm{s})$. The plasma is expected to stay in LTE throughout the test-section [13]. We measured a spectrum from $250 \mathrm{~nm}$ to $800 \mathrm{~nm}$ and compared it with the LTE spectrum computed with SPECAIR [18]. Results at $15 \mathrm{~cm}$ are presented in Figure 3. The good agreement between the experimental and computed LTE spectra supports the equilibrium assumption for this case. Note that, for this case, all temperature measurements agree within another. We present here only the spectrum measured at the center of the tube (i.e. the Abel-inverted spectrum at radial position $\mathrm{r}=0 \mathrm{~cm}$ ), but we observed similar agreement across the tube for all Abel-inverted spectra. 


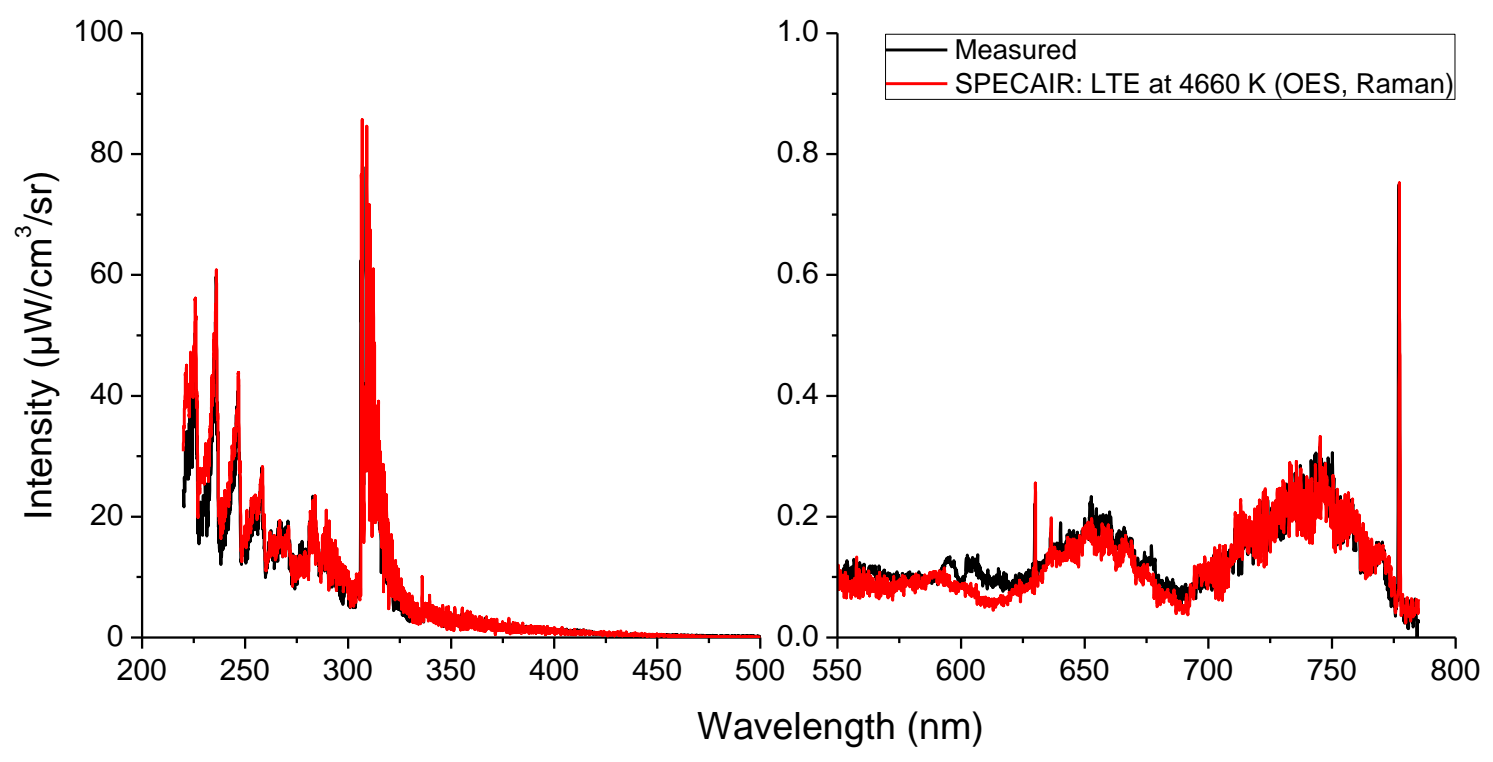

Figure 3: Measured (black) and computed (red) spectrum at the exit of the $15-\mathrm{cm}$ tube for the Air/Ar plasma case.

\section{$\mathrm{N}_{2} /$ Ar low flowrate plasma:}

In this case, $1.2 \mathrm{~g} / \mathrm{s}$ of nitrogen is premixed with $1.5 \mathrm{~g} / \mathrm{s}$ of argon. In previous work [13], we measured the emission spectrum between 500 and $800 \mathrm{~nm}$ and we observed a departure from chemical equilibrium at 10 and $15 \mathrm{~cm}$ leading to an overpopulation of the vibrational levels of $\mathrm{N}_{2}(\mathrm{~B})$. Here we extend these measurements from 250 to $900 \mathrm{~nm}$ in order to (a) validate the previous measurements, (b) access vibrational level $\mathrm{v}=1$ of $\mathrm{N}_{2}(\mathrm{~B})$ at $870 \mathrm{~nm}$, and (c) measure the transitions of $\mathrm{N}_{2}(\mathrm{C}) \rightarrow \mathrm{N}_{2}(\mathrm{~B})$ and $\mathrm{N}_{2}{ }^{+}(\mathrm{B})$ $\rightarrow \mathrm{N}_{2}{ }^{+}(\mathrm{X})$ between 280 and $450 \mathrm{~nm}$. We used the CEA code [19] to calculate the equilibrium composition of the plasma at the temperature measured using Raman spectroscopy. Details on the Raman spectroscopy measurements are given in our previous publication [20]. We use the radiation code SPECAIR to compute equilibrium spectra with the given composition and temperature. We observe a large difference between the measured spectrum and the spectrum computed assuming equilibrium. Using an optimization algorithm coupled with Specair, we adjusted the populations of the vibrational levels of $\mathrm{N}_{2}(\mathrm{C}), \mathrm{N}_{2}{ }^{+}(\mathrm{B})$ and $\mathrm{N}_{2}$ (B) to match the measured emission spectra. This optimization algorithm minimizes the $\mathrm{L}_{2}$ error between the experimental and computed spectra using a truncated Newton method.

To quantify the uncertainties, we used the following method: first a random noise was added to the computed spectra. The amplitude of the noise was adjusted to match the experimental uncertainty, found as the addition of the measured random noise and the uncertainties coming from the Abel inversion algorithm. The uncertainties vary from experiment to experiment, but the typical value is $5 \%$ at the centerline of the tube and below $30 \%$ elsewhere. Then the optimization algorithm was run on these new spectra and the error from the best fit was computed. This was performed a total of 100 times for each spectrum. Above 100 times both the standard deviation and the mean of the error did not change significantly and therefore 100 times was found to be sufficient. The standard deviation of the results was taken as the uncertainty on the measurement. This procedure tests the sensitivity of our algorithm to the experimental noise and yields a good estimate of the uncertainty of the fits. In figure 4, we plot the measured spectrum, the computed spectrum using SPECAIR assuming equilibrium, and the spectrum resulting from the optimization algorithm at the exit of the 10-cm tube. We also show the fitted populations of the vibrational levels of $\mathrm{N}_{2}(\mathrm{C}), \mathrm{N}_{2}{ }^{+}(\mathrm{B})$ and $\mathrm{N}_{2}(\mathrm{~B})$ used for the SPECAIR calculations. 
The plasma is near equilibrium but there is a slight overpopulation of the vibrational levels of $\mathrm{N}_{2}(C)$, $\mathrm{N}_{2}{ }^{+}(\mathrm{B})$ and $\mathrm{N}_{2}(\mathrm{~B})$.
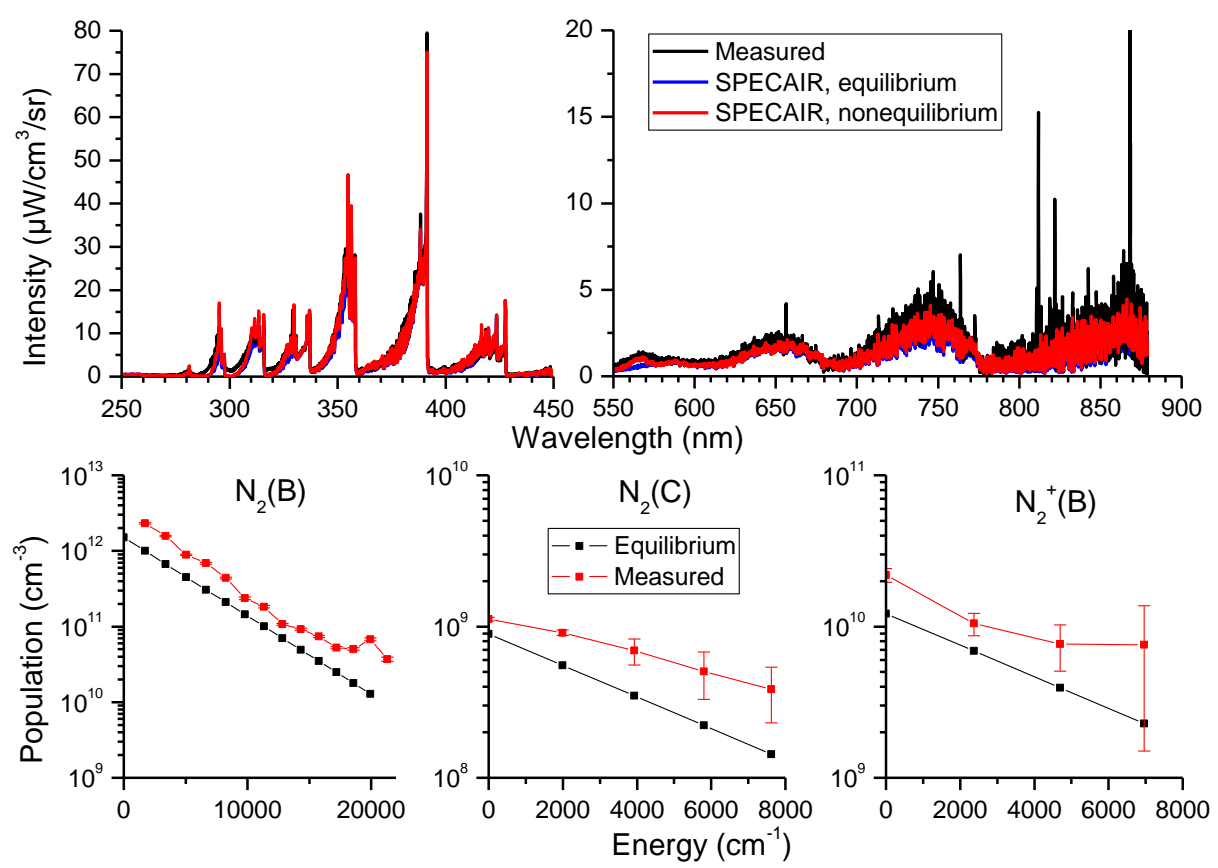

Figure 4: Top: comparison between measured and computed spectra at the exit of the 10-cm tube for the $\mathrm{N}_{2} / \mathrm{Ar}$ low flowrate case at the center of the tube $(\mathrm{r}=0 \mathrm{~cm})$. Equilibrium spectrum (blue) and fitted spectrum (red). Bottom: equilibrium and measured populations of emitting levels used for SPECAIR calculations.

We performed the same measurements at the exit of the $15-\mathrm{cm}$ tube. Results are shown in Figure 5 . We observe larger vibrational overpopulations of $\mathrm{N}_{2}(\mathrm{C}), \mathrm{N}_{2}{ }^{+}(\mathrm{B})$ and $\mathrm{N}_{2}(\mathrm{~B})$ than for the 10-cm tube. Chemical nonequilibrium therefore increases with axial position. Note the presence of NO systems between 250 and $300 \mathrm{~nm}$. This is explained by the presence of small quantities of water vapor impurities in the injection gas. Results are in good agreement if we add approximately $1 \%$ mole fraction of water into the plasma. 

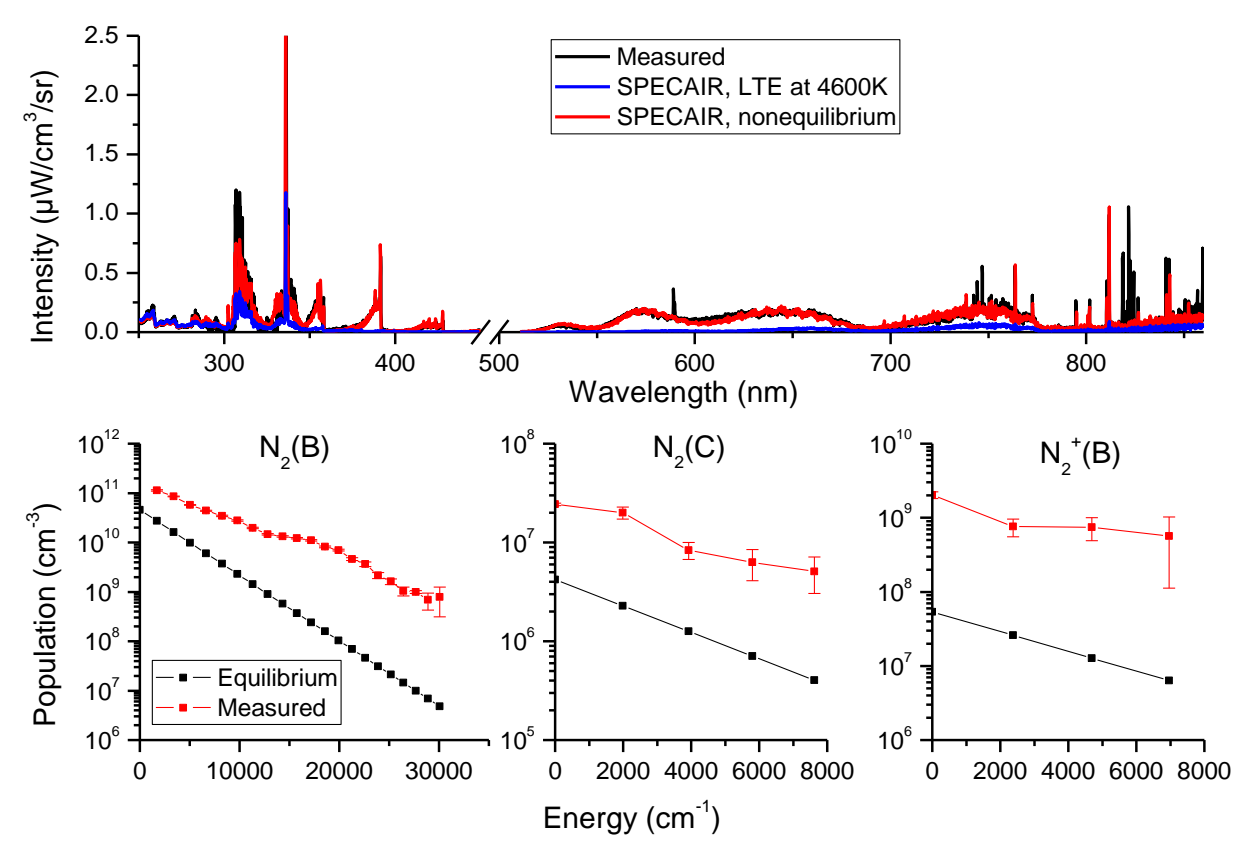

Figure 5: Top: comparison between measured and computed spectra at the exit of the 15-cm tube for the $\mathrm{N}_{2} /$ Ar low flowrate case at the center of the tube $(\mathrm{r}=0 \mathrm{~cm})$. Equilibrium spectrum (blue) and fitted spectrum (red). Bottom: equilibrium and measured populations of emitting levels used for SPECAIR calculations.

We only present here the results for the centerline of the tube. However, this fitting procedure was performed for all spectra and as a function of radius. We also performed this analysis for all spectral bands observed, which correspond to emission from various vibrational levels of $\mathrm{N}_{2}(\mathrm{~B}), \mathrm{N}_{2}(\mathrm{C})$ and $\mathrm{N}_{2}{ }^{+}(\mathrm{B})$. This enabled us to obtain the absolute populations of these states as a function of both radius and axial distance (i.e. tube length). The results for $\mathrm{N}_{2}(\mathrm{~B})$ are similar to the results of Ref. [13] and therefore will not be presented here. For $\mathrm{N}_{2}(\mathrm{C})$ and $\mathrm{N}_{2}{ }^{+}(\mathrm{B})$, we present the radial distribution of vibrational levels densities for each axial position in Appendix A.

From a modeling perspective, it is important to correctly predict the populations of the excited states as the total radiation is proportional to these populations. Hypersonic CFD codes for atmospheric reentry often use multi-temperature models such as the 2-temperature model proposed by Park [6] [21] [22] [23]. This model uses a translational-rotational temperature $T_{\text {tr }}$ and a vibrational-electronic temperature $\mathrm{T}_{\mathrm{ve}}$. The R-T relaxation times are assumed to be fast enough to consider a single temperature for translation and rotation, and likewise for the vibrational and electronic temperature. Vibrationaltranslational (VT) relaxation is determined using the Landau-Teller equation:

$$
\frac{d E_{v e, s}}{d t}=\sum_{c}\left(x_{c} \frac{E_{v e, s}\left(T_{t r}\right)-E_{v e, s}\left(T_{v e}\right)}{\tau_{V-T}^{s-c}}\right)
$$

where $E_{v e, s}$ is the vibrational-electronic energy of species s, $x_{c}$ the mole fraction of species c, and $\tau_{V-T}^{S-c}$ the relaxation time of species s colliding with species $\mathrm{c}$ in their ground state. The relaxation time is determined using the correlations given in the literature [24] [25]. Note that we make the simplifying assumptions that the VT time is the same for all electronic states of the considered species, and that the electronic states are in Boltzmann equilibrium with the ground state at the given $\mathrm{T}_{\mathrm{ve}}$.

We performed a 0-D simulation with the 2-temperature model from 0 to $15 \mathrm{~cm}$ along the centerline of the flow. The axial profile of translational temperature is obtained from a cubic interpolation of the 
temperatures measured with Raman spectroscopy at 0,10 , and $15 \mathrm{~cm}$ (see Figure 6). The radial velocity profile is obtained by self-similarity with the temperature profile, as discussed and calculated in Ref. [13]. The centerline velocity at $x=0 \mathrm{~cm}$ is about $800 \mathrm{~m} / \mathrm{s}$ and about $500 \mathrm{~m} / \mathrm{s}$ at $\mathrm{x}=15 \mathrm{~cm}$. Three species are considered, $\mathrm{N}_{2}, \mathrm{~N}$, and argon. We consider uncertainties on the measured translational temperatures (about $5 \%$ at $0 \mathrm{~cm}$, and $10 \%$ at 10 and $15 \mathrm{~cm}$ ), on the shape of the interpolated temperature profile, and on the velocity (about 20\%). Given these uncertainties, the Landau-Teller model gives $\mathrm{T}_{\mathrm{ve}}=5950 \pm$ $200 \mathrm{~K}$ at $10 \mathrm{~cm}$ and $5000 \pm 150 \mathrm{~K}$ at $15 \mathrm{~cm}$. The different translational temperature profiles taken in the calculations and the resulting vibrational temperature profiles are shown in Figure 6.

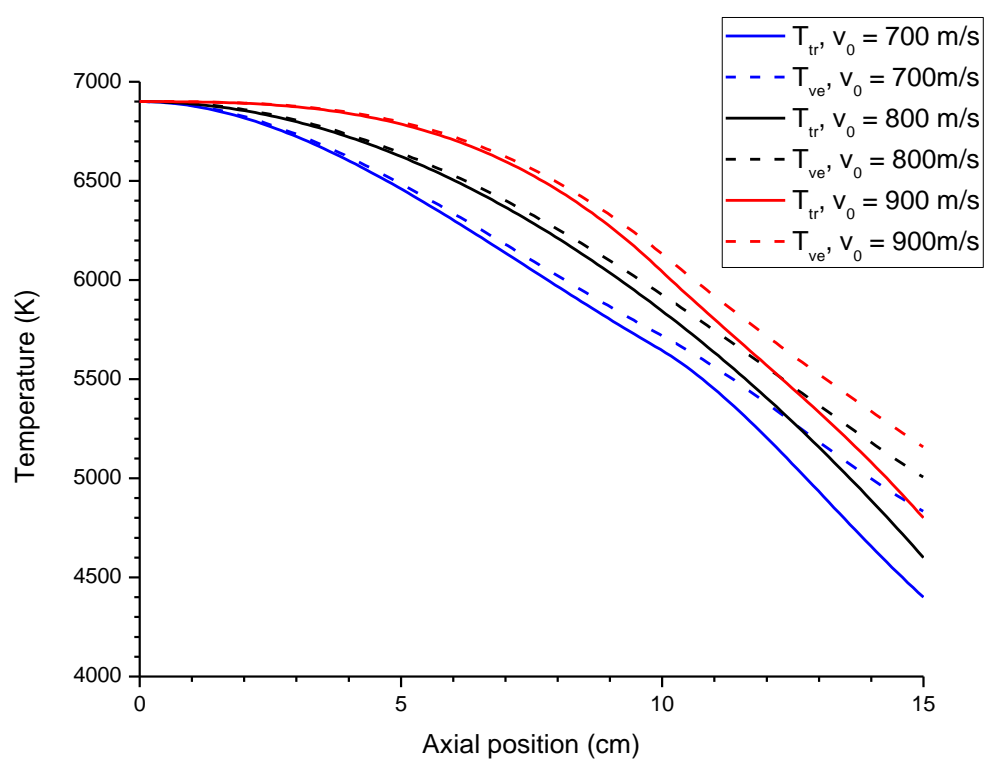

Figure 6: Translational temperature profiles (solid lines) based on the measured Raman temperatures, and vibrational temperature profiles (dashed lines) obtained from the LandauTeller model for the $\mathrm{N}_{2} / \mathrm{Ar}$ low flowrate case. The black curves correspond to the nominal case. The red and blue curves represent the upper and lower uncertainty bounds, respectively.

Figure 7 shows the measured vibrational population distributions of the $\mathrm{N}_{2}$ states at 0,10 and $15 \mathrm{~cm}$, along with the distributions corresponding to equilibrium and those obtained with the 2-temperature model. The populations of the first three vibrational levels of $\mathrm{N}_{2}(\mathrm{X})$ were measured by Raman spectroscopy in our previous work [20] and the rotational and vibrational temperatures of $\mathrm{N}_{2}(\mathrm{X})$ were found to be equal. Therefore, the rotational and vibrational distribution of $\mathrm{N}_{2}(X)$ are assumed to follow a Boltzmann distribution at the measured temperature. In all cases, the equilibrium distribution largely underestimates the measured populations. At $10 \mathrm{~cm}$, the populations computed using the 2-T model underestimate the measurements by a factor of about 3 . At $15 \mathrm{~cm}$, better agreement is found for the first vibrational levels of $\mathrm{N}_{2} \mathrm{~B}$ and $\mathrm{N}_{2} \mathrm{C}$. However, a large discrepancy is observed for the higher vibrational levels of $\mathrm{N}_{2} \mathrm{~B}$. This is because the $\mathrm{N}_{2}(\mathrm{~B}, \mathrm{v}=13)$ vibrational level is populated by inverse predissociation of $\mathrm{N}\left({ }^{4} \mathrm{~S}\right)$, and therefore its overpopulation with respect to equilibrium varies as the square of the overpopulation of nitrogen atoms, as explained in Ref [12]. Since the atomic nitrogen population is nearly frozen along the axis of the tube, the overpopulation of $N\left({ }^{4} \mathrm{~S}\right)$ increases strongly along the axis of the tube. Therefore, the departure from the 2-temperature model predictions becomes stronger at 15 $\mathrm{cm}$ than at $10 \mathrm{~cm}$. This mechanism of inverse predissociation is of course not considered in the 2-T model. 

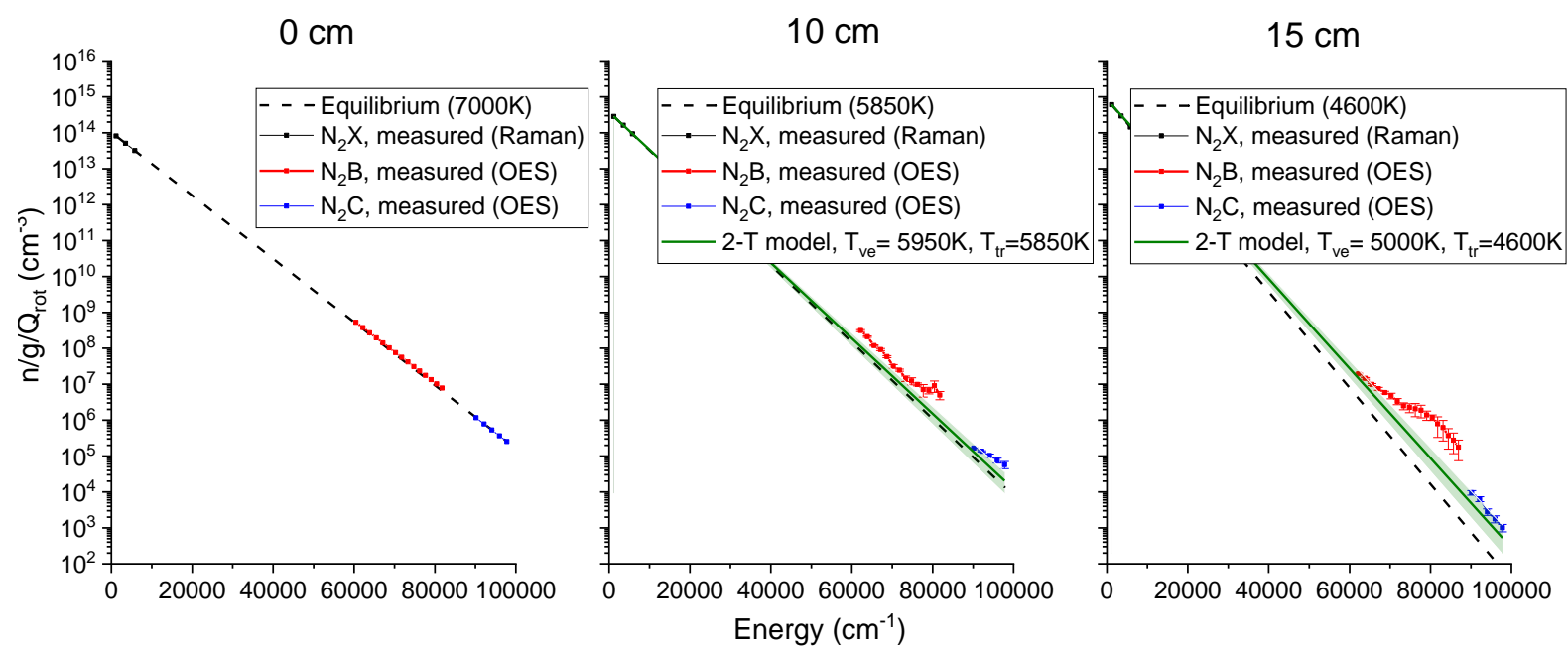

Figure 7: Comparison between the population distributions computed using the 2-temperature model (green) and the measurements (symbols) for the $\mathrm{N}_{2}$ /Ar low flowrate case. The green shaded swaths represent the uncertainty bands on the computed $\mathbf{T}_{\text {ve. }}$.

The radiation emitted by the plasma is proportional to the population of the excited states. Figure 8 compares the integrated intensity from 250 to $900 \mathrm{~nm}$ for the measured, equilibrium, and 2-T spectra. At $15 \mathrm{~cm}$, the measured total radiation is about 4 times stronger than equilibrium, and 1.5 times larger than with the 2-T model. Thus, the 2-T model improves the radiation predictions. This experiment represents a case where the plasma stays relatively close to equilibrium but with still non-negligible nonequilibrium radiation. This is therefore a useful test case for numerical codes to check their ability to predict the radiation when a small departure from equilibrium is induced.

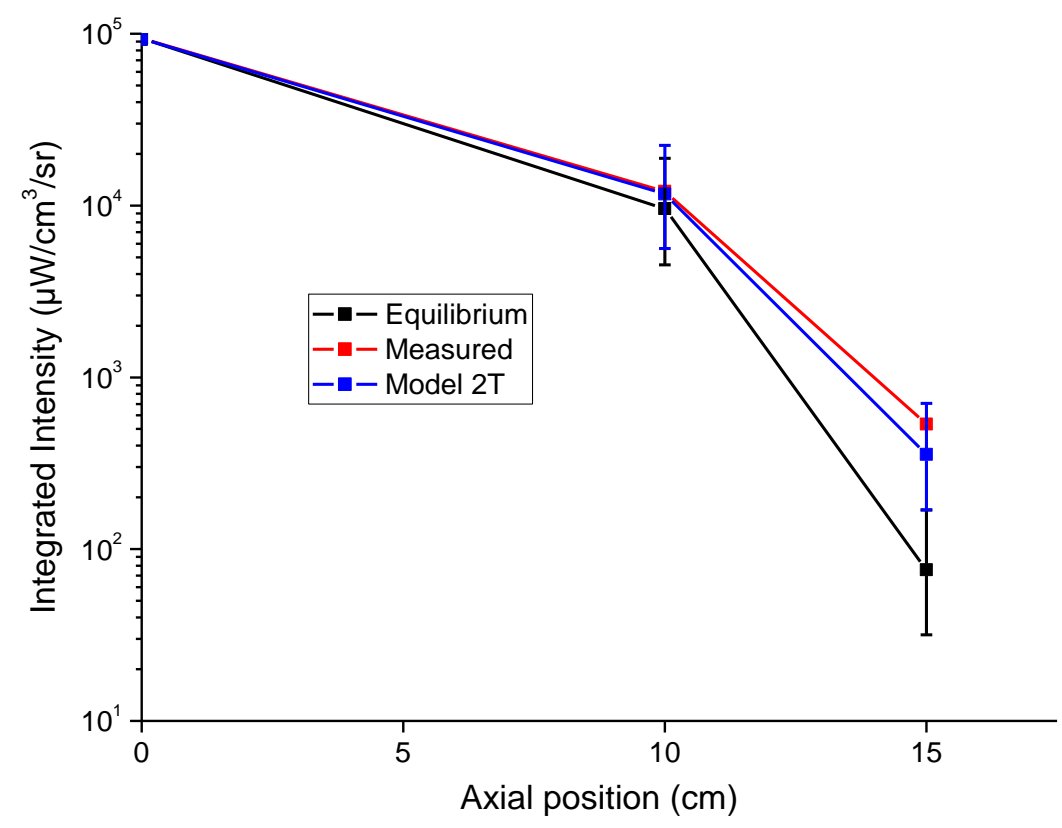

Figure 8: Radiative intensity (integrated between 250 and $900 \mathrm{~nm}$ ) of the measured, equilibrium and 2-T spectra for the $\mathrm{N}_{2} / \mathrm{Ar}$ low flowrate case.

$\mathrm{N}_{2} /$ Ar high flowrate plasma: 
In this case, $1.9 \mathrm{~g} / \mathrm{s}$ of nitrogen is premixed with $1.5 \mathrm{~g} / \mathrm{s}$ of argon. Using the spectrum measured between 250 and $900 \mathrm{~nm}$, we extract with our fitting routine the populations of the vibrational levels of $\mathrm{N}_{2}(\mathrm{C})$, $\mathrm{N}_{2}{ }^{+}(\mathrm{B})$ and $\mathrm{N}_{2}(\mathrm{~B})$. Figure 9 shows the results at the exit of the 10-cm tube. We observe a larger departure from equilibrium than in the low flowrate case. This was already observed for $\mathrm{N}_{2}$ (B) in Ref. [12] and there is a similar trend for $\mathrm{N}_{2}(\mathrm{C})$ and $\mathrm{N}_{2}{ }^{+}(\mathrm{B})$. Results at $15 \mathrm{~cm}$ are presented in Figure 10. The vibrational levels of excited states of nitrogen are highly overpopulated relative to their equilibrium populations. The vibrational population distributions of $\mathrm{N}_{2}(\mathrm{C})$ and $\mathrm{N}_{2}{ }^{+}(\mathrm{B})$ measured at each radial and axial position are presented in detail in Appendix A.
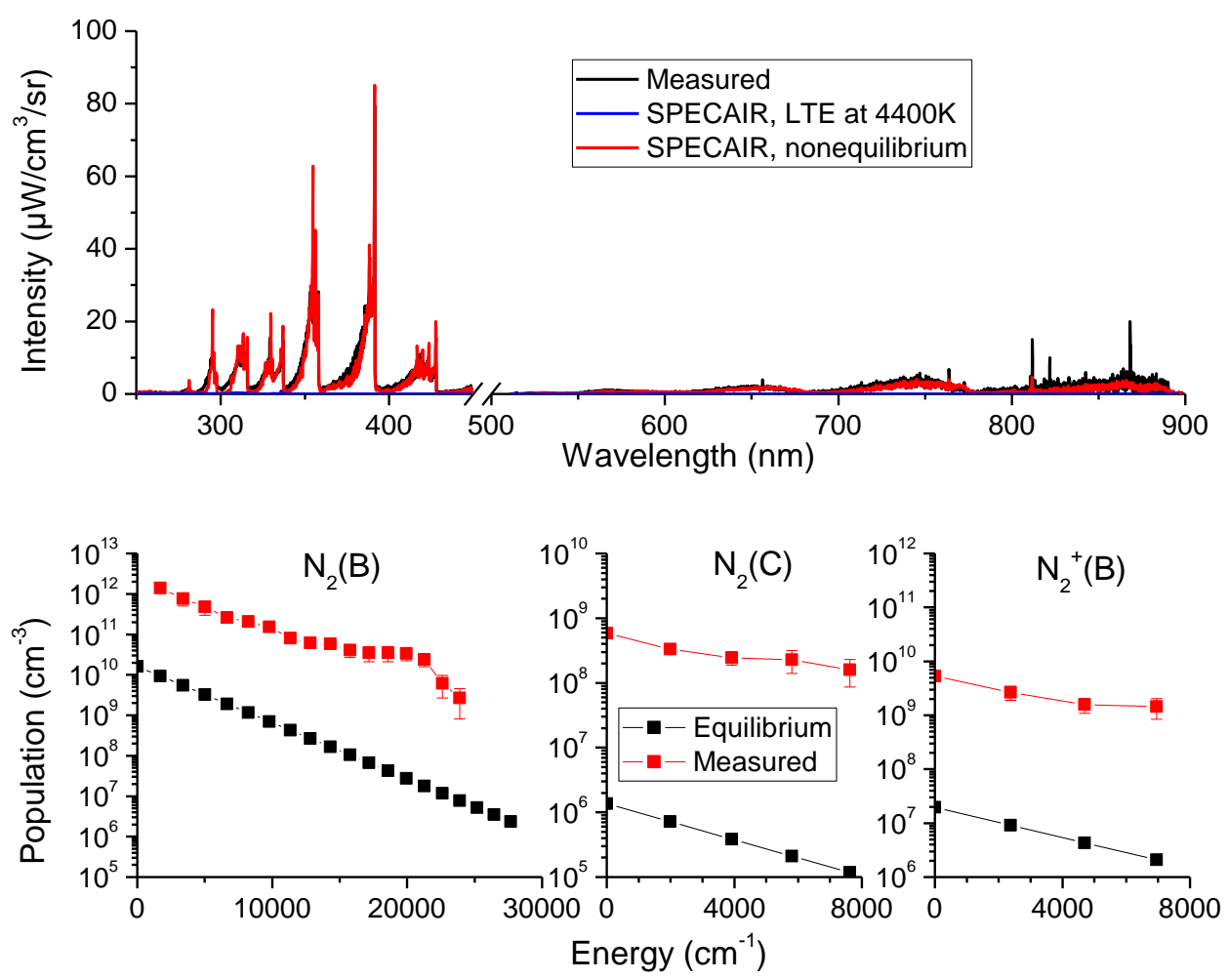

Figure 9: Top: comparison between measured and computed spectra at the exit of the 10-cm tube (at $\mathbf{r}=\mathbf{0} \mathrm{cm}$ ) for the $\mathrm{N}_{2} / \mathrm{Ar}$ high flowrate case. Equilibrium spectrum (blue) and fitted spectrum (red). Bottom: equilibrium and measured populations of emitting levels used for SPECAIR calculations. 

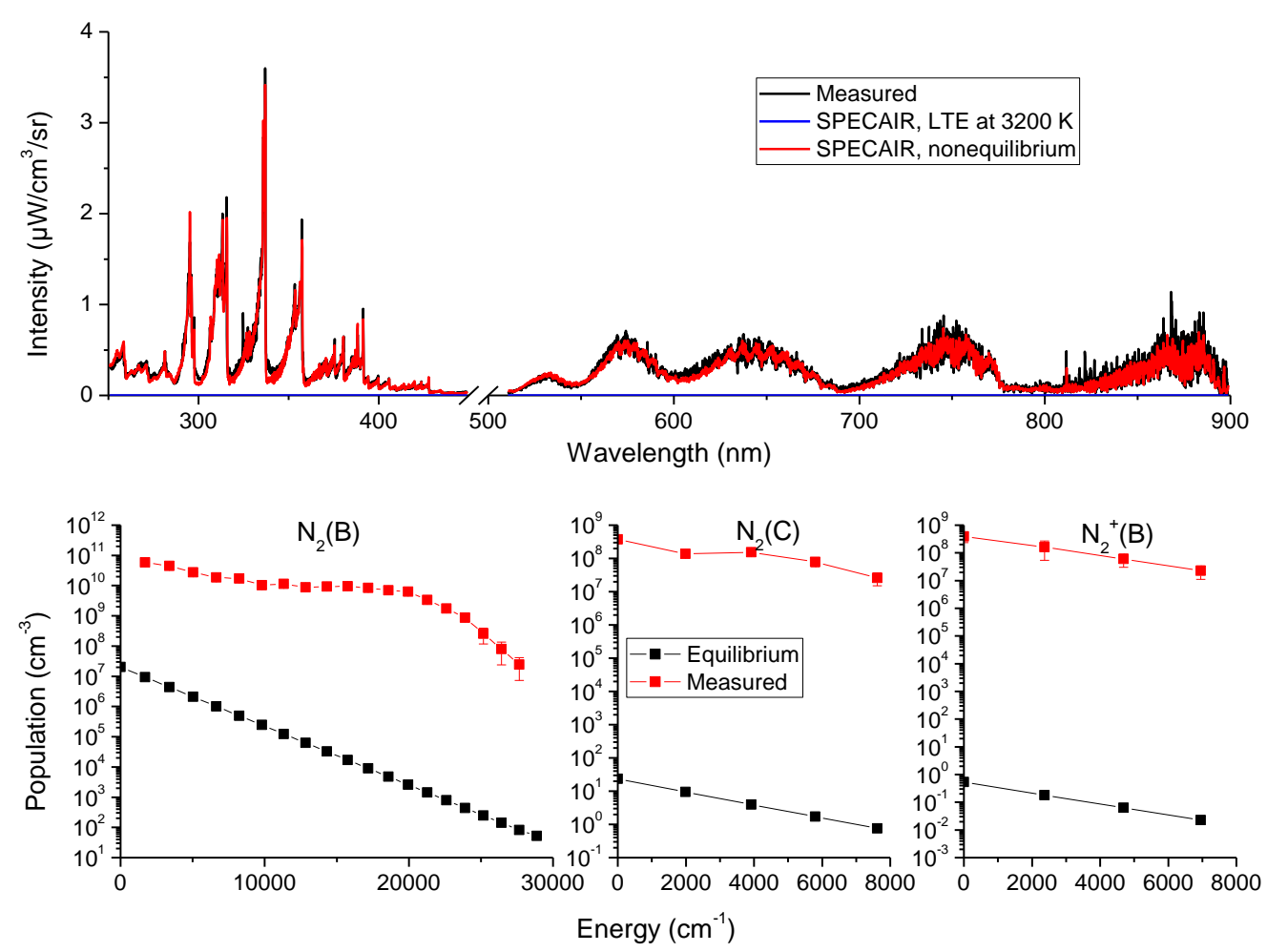

Figure 10: Top: comparison between measured and computed spectra at the exit of the 15-cm tube $(r=0 \mathrm{~cm})$ for the $\mathrm{N}_{2} / \mathrm{Ar}$ high flowrate case. Equilibrium spectrum (blue) and fitted spectrum (red). Bottom: equilibrium and measured populations of emitting levels used for SPECAIR calculations.

The Boltzmann plot shown in Figure 11 summarizes the population distributions of the various states measured, namely $\mathrm{N}_{2}(\mathrm{X}), \mathrm{N}_{2}(\mathrm{~B})$ and $\mathrm{N}_{2}(\mathrm{C})$. We performed the same analysis as for the low flowrate case using a 2-T model and obtained $\mathrm{T}_{\mathrm{ve}}=4700 \pm 300 \mathrm{~K}$ at $15 \mathrm{~cm}$. The corresponding distribution is also plotted in Figure 11. The chemistry is partly frozen in the tube, because the excited state densities do not change significantly along the axis of the tube. Note also that the population density remains fairly continuous between the $\mathrm{N}_{2}(\mathrm{~B})$ and $\mathrm{N}_{2}(\mathrm{C})$ states. The 2-T model is closer to the experimental values than the equilibrium distribution, but discrepancies still appear at $10 \mathrm{~cm}$ and for higher energy levels at $15 \mathrm{~cm}$. The non-Boltzmann distribution cannot be predicted using a $2 \mathrm{~T}$ model. Therefore, a detailed vibrational specific kinetic model must be used in order to predict the measured distributions. 

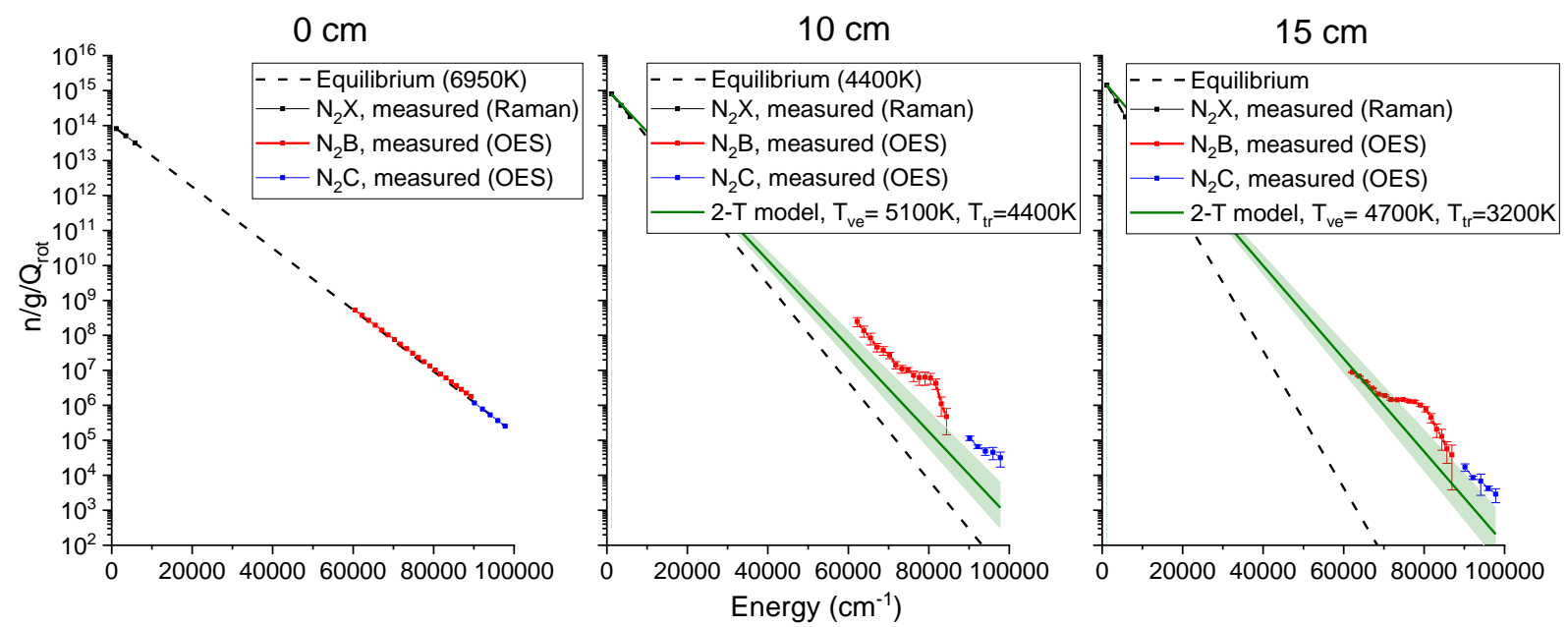

Figure 11: Comparison between the population distributions computed using the 2-temperature model (green) and the measurements (symbols) for the $\mathrm{N}_{2} / \mathrm{Ar}$ HF case. The green shaded swaths represent the uncertainty bands on the computed $T_{\text {ve }}$.

Figure 12 shows the volumetric emission at the centerline of the plasma flow, integrated between 250 to $900 \mathrm{~nm}$, obtained from the measurements, from the 2-T model, and from equilibrium population distributions. At $10 \mathrm{~cm}$, the equilibrium radiation is 250 times smaller than the measurements and about 100,000 times smaller at $15 \mathrm{~cm}$. The 2-T model improves the agreement with an underprediction by a factor of 13 at $10 \mathrm{~cm}$ and a factor of about 6 at $15 \mathrm{~cm}$. The 2-T model is therefore unable to correctly predict the radiation coming from such recombining plasma flows.

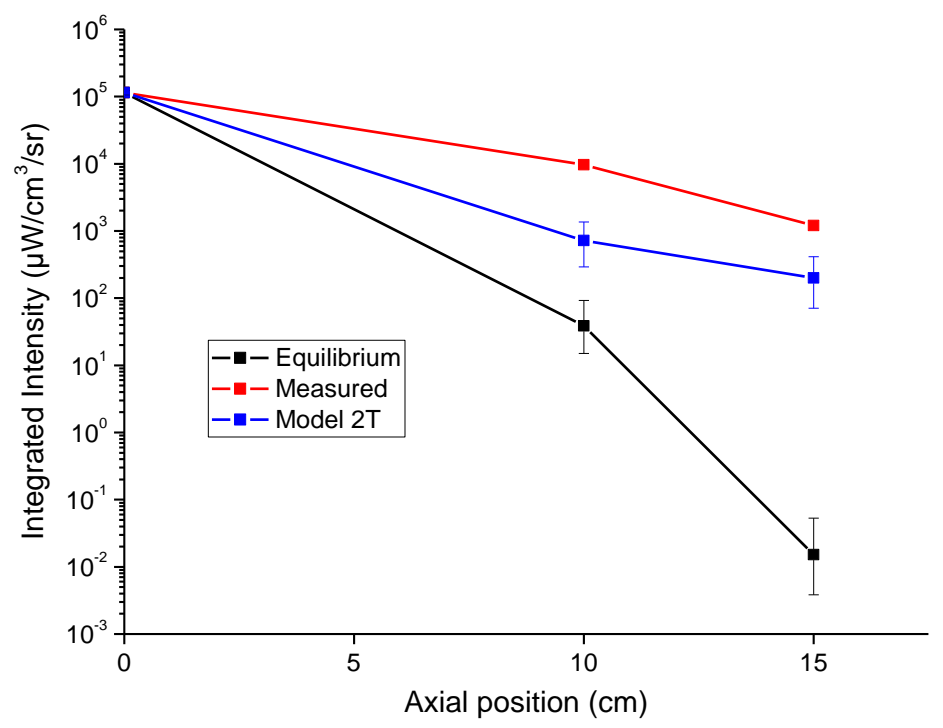

Figure 12: Comparison between the integrated intensity assuming equilibrium (at the measured temperature) and the measured one between 250 and $900 \mathrm{~nm}$ for the $\mathrm{N}_{2} / \mathrm{Ar} \mathrm{HF}$ case.

\section{Discussion}

In both $\mathrm{N}_{2} / \mathrm{Ar}$ mixtures studied, the excited states of nitrogen were found to be highly overpopulated as compared to both equilibrium and 2-T model predictions. The main reason is believed to be the inverse predissociation of $\mathrm{N}\left({ }^{4} \mathrm{~S}\right)$ into $\mathrm{N}_{2}(\mathrm{~B}, \mathrm{v}=13)$ as explained in ref [12].

Potentially, other reactions could also play a role as discussed in other papers. For example, Capitelli et al [26] showed that the population distribution of excited electronic states is sometimes affected by 
superelastic electron collisions. However, they simulated conditions close to those of our experiments and found that superelastic collisions have no influence under our conditions.

Plain et al [27] reported that coupling effects between high-lying vibrational levels of $\mathrm{N}_{2}(\mathrm{X})$ and $\mathrm{N}_{2}(\mathrm{~B})$ could affect the excited electronic state population distributions. This cannot be proven for the moment as our measurement of the vibrational level of $\mathrm{N}_{2}(X)$ using Raman spectroscopy only yields results for low vibrational levels. A more sensitive diagnostic, e.g. CARS [28], would be necessary to gain access to higher-lying vibrational levels. In addition, measuring precisely the rotational distribution of $\mathrm{N}_{2}(\mathrm{X})$ could also be relevant to confirm the predictions of Panesi et al [29] who found the rotational and vibrational temperatures of $\mathrm{N}_{2}(\mathrm{X})$ to differ under certain conditions.

Finally, it should be noted that the chemistry in our experiments is partly frozen and therefore the recombination kinetics are slow. This explains why the 2-T model improves the agreement between the experiments and the predictions. However, this model is expected to give worse results in a case where recombination is faster. A detailed kinetic model is currently under development to simulate the experimental results reported here.

\section{Conclusions}

New experiments were performed in our plasma torch facility to measure emission from both equilibrium and nonequilibrium $\mathrm{N}_{2} / \mathrm{Ar}$ and Air/Ar plasmas. Optical emission spectroscopy was used to measure spectra of the plasmas between 250 and $900 \mathrm{~nm}$ for three different test cases: a mixture of Air/Ar and two cases with $\mathrm{N}_{2} / \mathrm{Ar}$ at low and high flowrates. For the Air/Ar mixture, the emission spectra agreed with those computed assuming equilibrium. This was expected as the plasma stays in equilibrium for this case. For the $\mathrm{N}_{2} / \mathrm{Ar}$ mixtures, the plasma was found to be out of equilibrium. We were able to determine the vibrational population distributions of $\mathrm{N}_{2}(\mathrm{~B}), \mathrm{N}_{2}(\mathrm{C})$ and $\mathrm{N}_{2}{ }^{+}(\mathrm{B})$ using SPECAIR and the measured spectra. These states were found to be overpopulated relative to equilibrium.

Finally, the measured radiation was integrated over the measured range of wavelength. This allows us to get the radiative heat flux which is the important property to model for reentry applications. Hypersonic CFD codes often use multiple temperatures models. Here, a 2-temperature model was employed to compare predictions with experiments. This was done using the Landau-Teller equation to compute the relaxation of the vibrational temperature to the translational one. Due to the rapid decrease in translational-rotational temperature, the vibrational temperature does not relax fast enough to equilibrate with the translational temperature. We compared the measured radiation with the 2temperature model predictions and with equilibrium predictions. The measured radiation was found to be up to 100,000 times higher than equilibrium. The agreement with the 2-T model was much better, however this model still underestimates the measured radiation by an order of magnitude and is expected to be worse in a real entry scenario. This is an important consideration for reentry applications. Note also that due to the non-Boltzmann vibrational distribution of the population of states such as $\mathrm{N}_{2} \mathrm{~B}$, only a vibrational specific kinetic model coupled to a CFD code will be able to correctly predict the radiation in recombining flows.

\section{Acknowledgments}

This work has been supported by Ariane Group, under a CIFRE Ph.D. grant (number 42701092/20160218/JSE), with Dr. Laurent Visconti as Technical Monitor.

\section{Appendix A: Radial profiles of vibrational populations of $\mathrm{N}_{2}(B), \mathrm{N}_{2}(\mathrm{C})$ and $\mathrm{N}_{2}{ }^{+}(\mathrm{B})$}

In this appendix we present the radial distributions of vibrational populations for each case considered. This intends to serve as a test-case database for computational simulations. In Figures A1 and A2, we present the radial distribution of vibrational populations for the $\mathrm{N}_{2} / \mathrm{Ar}$ low flowrate (LF) case at 10 and 
$15 \mathrm{~cm}$, respectively. In Figures A3 and A4, we present the same results for the $\mathrm{N}_{2} / \mathrm{Ar}$ high flowrate (HF) case.
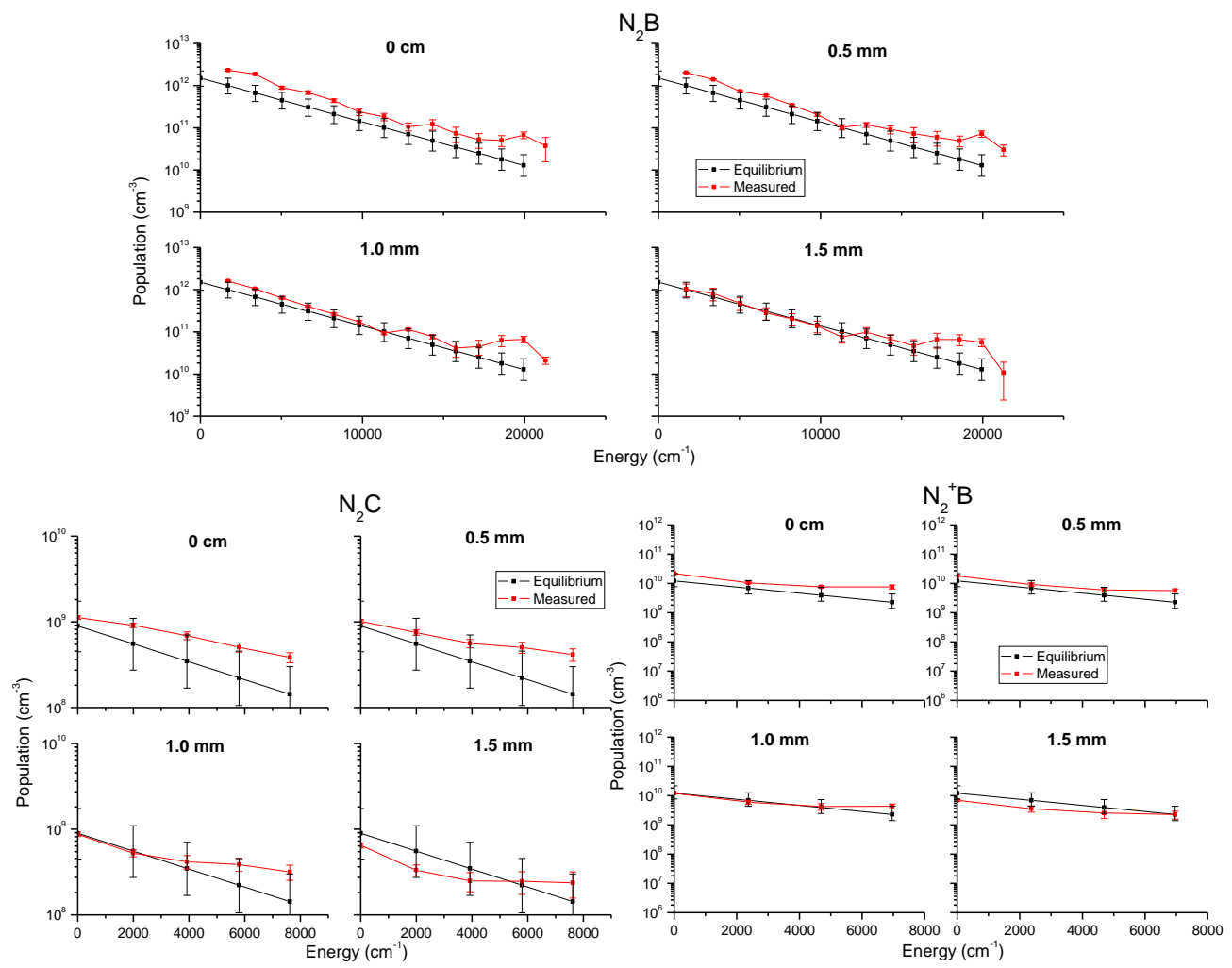

Figure A1: Radial distribution of measured and equilibrium densities of $\mathrm{N}_{2} \mathrm{~B}$ (top), $\mathrm{N}_{2} \mathrm{C}$ (bottom left) and $\mathrm{N}_{2}{ }^{+} \mathrm{B}$ (bottom right) for the $\mathrm{N}_{2} / \mathrm{Ar} \mathrm{LF}$ case at the exit of the $10-\mathrm{cm}$ tube. 

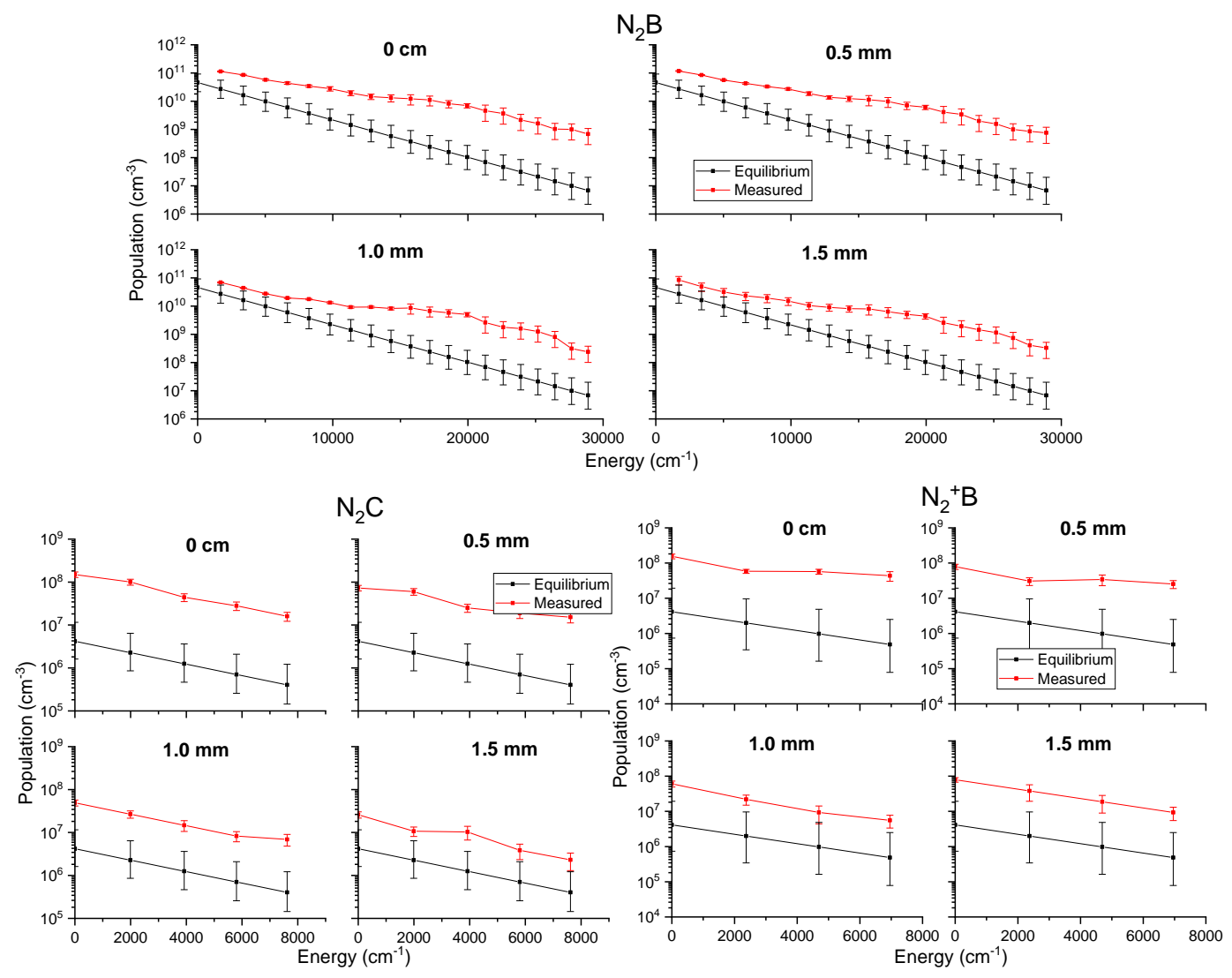

Figure A2: Radial distribution of measured and equilibrium densities of $\mathrm{N}_{2} \mathrm{~B}$ (top), $\mathrm{N}_{2} \mathrm{C}$ (bottom left) and $\mathrm{N}_{2}{ }^{+} \mathrm{B}$ (bottom right) for the $\mathrm{N}_{2} / \mathrm{Ar} \mathrm{LF}$ case at the exit of the $15-\mathrm{cm}$ tube.
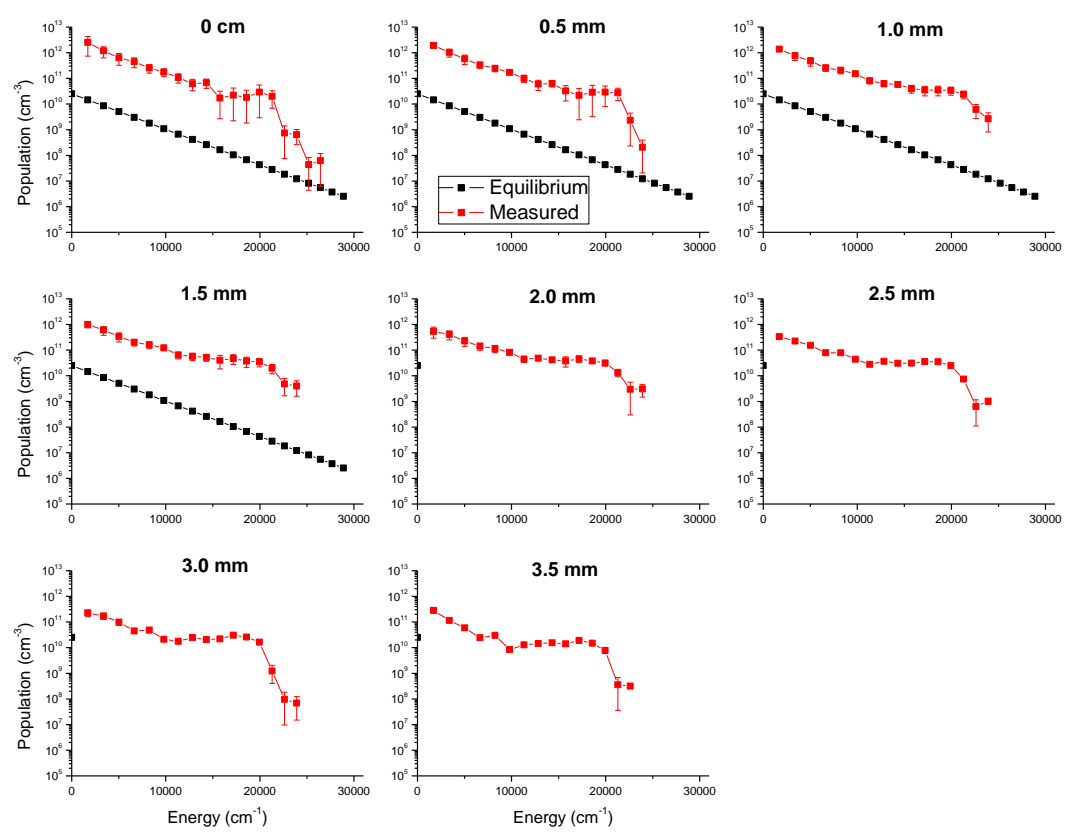

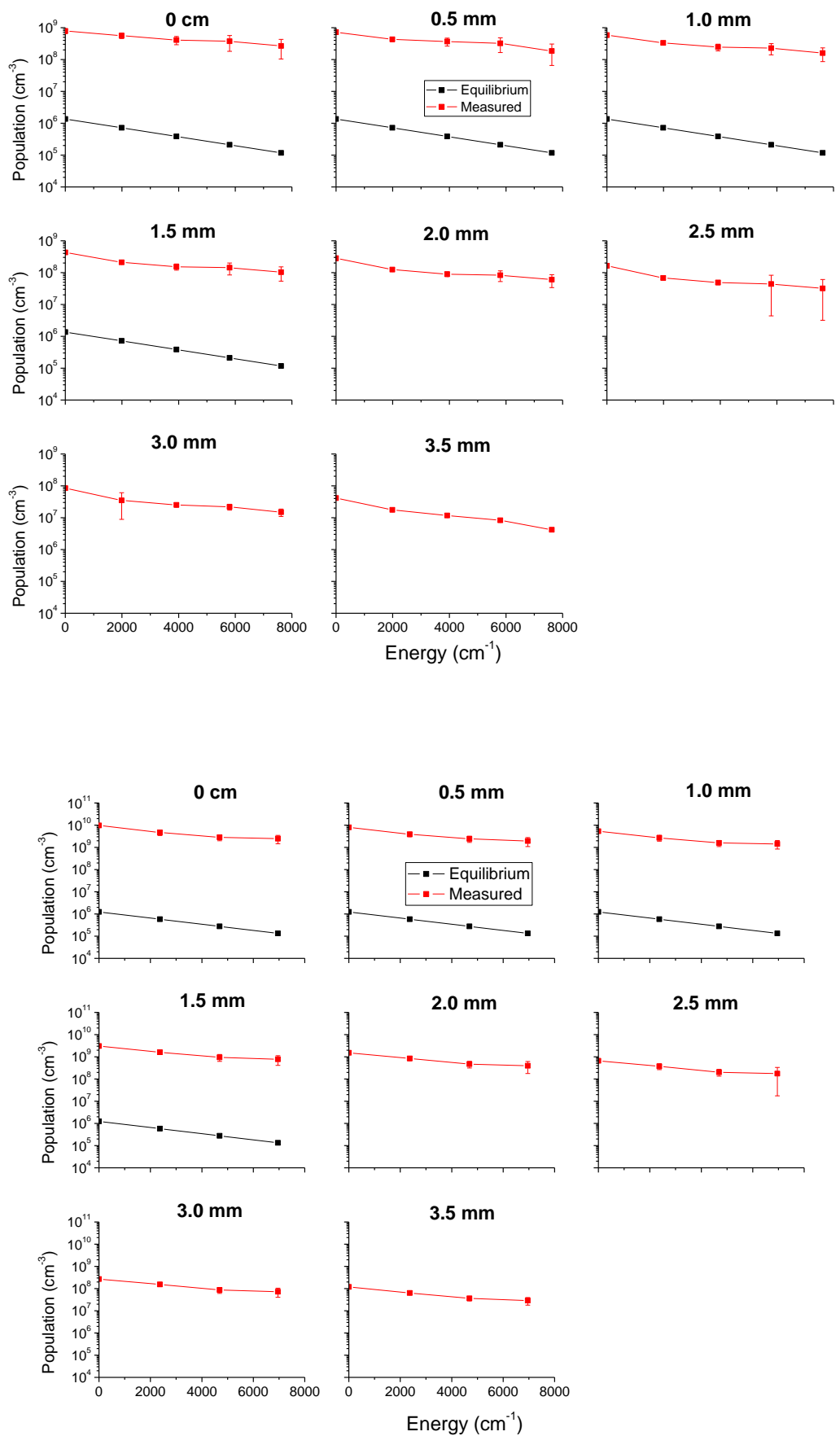

Figure A3: Radial distribution of measured and equilibrium densities of $\mathrm{N}_{2} \mathrm{~B}$ (top), $\mathrm{N}_{2} \mathrm{C}$ (middle) and $\mathrm{N}_{2}{ }^{+} \mathrm{B}$ (bottom) for the $\mathrm{N}_{2} / \mathrm{Ar} \mathrm{HF}$ case at the exit of the $10-\mathrm{cm}$ tube. 

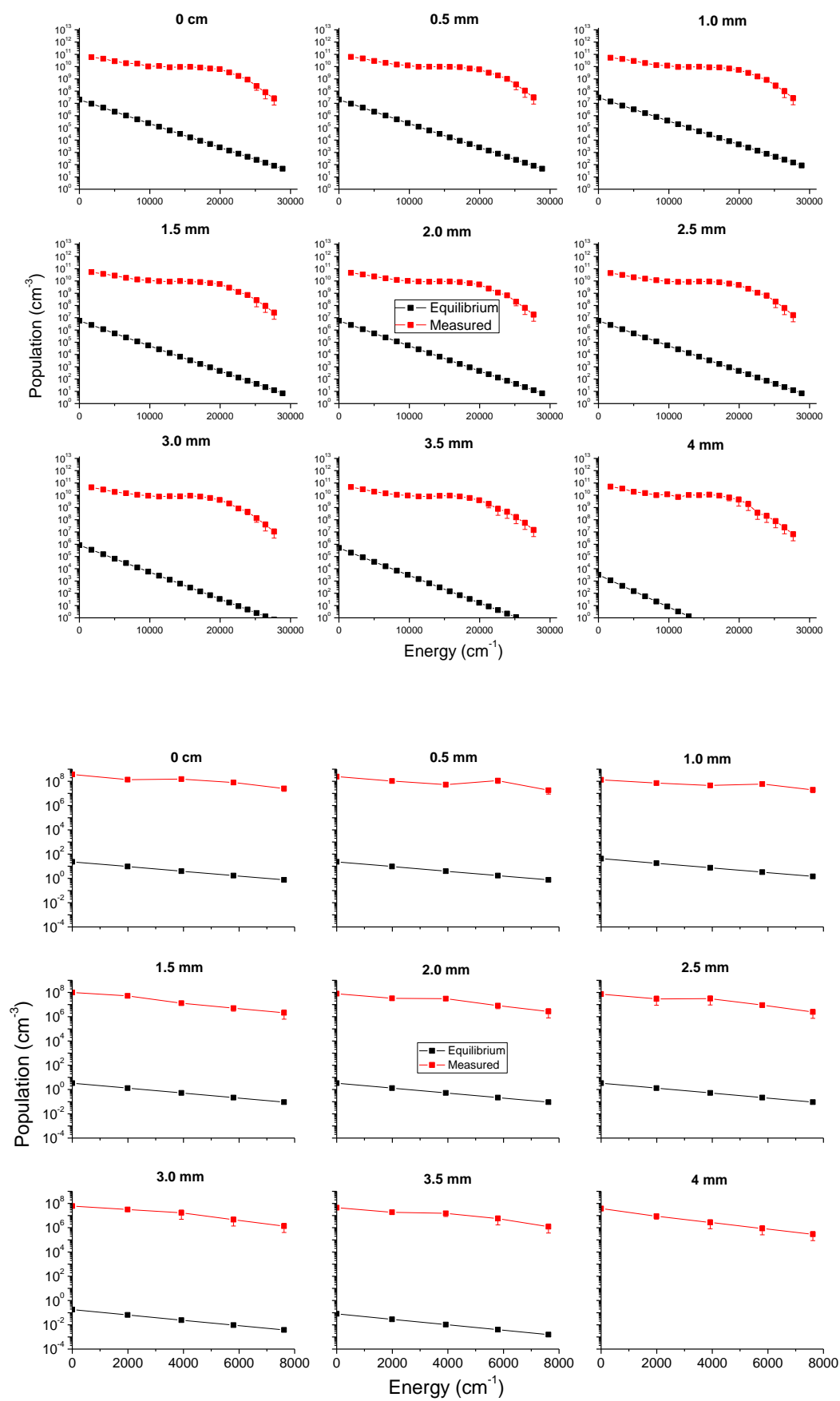


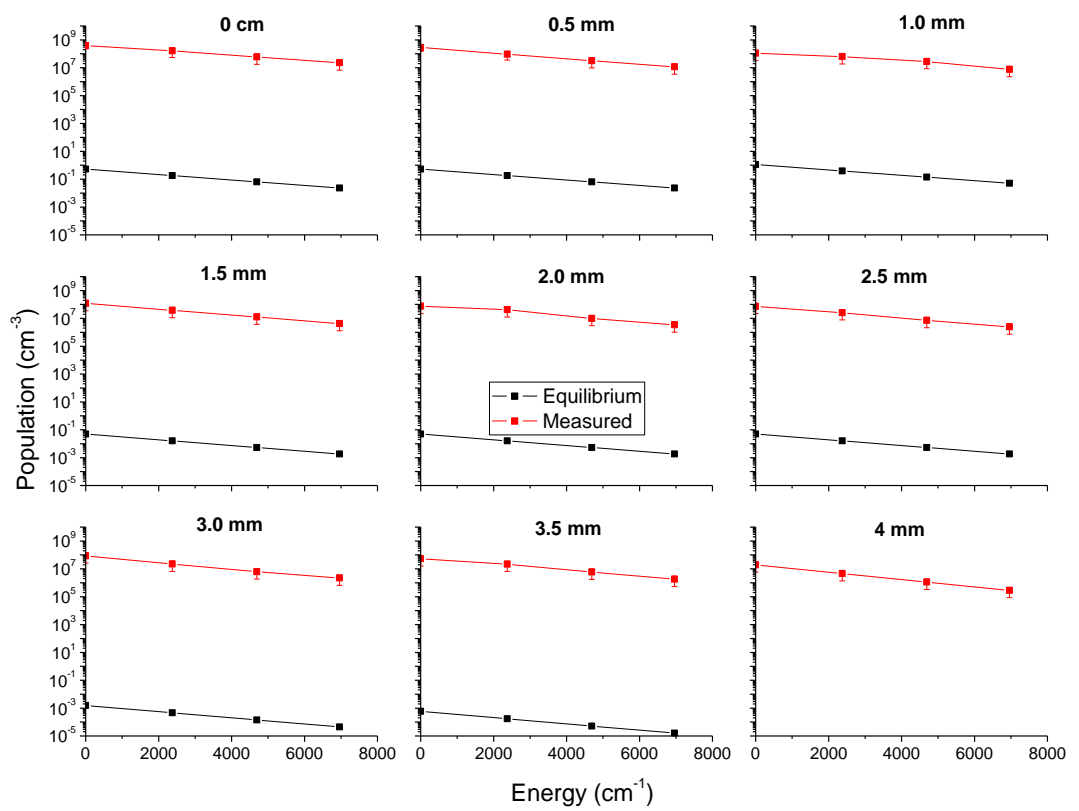

Figure A4: Radial distribution of measured and equilibrium densities of $\mathrm{N}_{2} \mathrm{~B}$ (top), $\mathrm{N}_{2} \mathrm{C}$ (middle) and $\mathrm{N}_{2}{ }^{+} \mathrm{B}$ (bottom) for the $\mathrm{N}_{2} / \mathrm{Ar} \mathrm{HF}$ case at the exit of the $15-\mathrm{cm}$ tube.

References

[1] C. Park, J. T. Howe, R. L. Jaffe and G. V. Candler, "Review of chemical-kinetic problems of future NASA missions. II - Mars entries," Journal of Thermophysics and Heat Transfer, vol. 8, no. 1, pp. 9-23, 1994.

[2] A. M. Brandis, C. O. Johnston, B. A. Cruden and D. K. Prabhu, "Investigation of Nonequilibrium Radiation for Mars Entry," 51st AIAA Aerospace Sciences Meeting including the New Horizons Forum and Aerospace Exposition, Aerospace Sciences Meetings, no. AIAA 2013-1055, 2013.

[3] C. O. Johnston, P. A. Gnoffo and A. Mazaheri, "Influence of Coupled Radiation and Ablation on the Aerothermodynamic Environment of Planetary Entry Vehicles," Radiation and Gas-Surface Interaction Phenomena in High Speed Re-Entry; 6-8- May 2013, 2013.

[4] C. O. Johnston and A. M. Brandis, "Features of Afterbody Radiative Heating for Earth Entry," Journal of Spacecraft and Rockets, vol. 52, no. 1, pp. 105-119, 2015.

[5] C. O. Johnston, A. M. Brandis and K. Sutton, "Shock Layer Radiation Modeling and Uncertainty for Mars entry," 43rd AIAA Thermophysics Conference, Fluid Dynamics and Co-located Conferences, no. AIAA 20122866, 2012.

[6] C. Park, Nonequilibrium hypersonic aerothermodynamics, New York: Wiley, 1989.

[7] C. O. Johnston and M. Panesi, "Refinements to Afterbody Radiative Heating Simulations for Earth Entry," 46th AIAA Thermophysics Conference, AIAA AVIATION Forum, no. AIAA 2016-3693, 2016.

[8] T. K. West and C. O. Johnston, "Uncertainty and Sensitivity Analysis of Afterbody Radiative Heating Predictions for Earth Entry," Journal of Thermophysics and Heat Transfer, vol. 31, no. 2, pp. 294-306, 2016.

[9] T. Hermann, S. Löhle, F. Zander, H. Fulge and S. Fasoulas, "Characterization of a Reentry Plasma WindTunnel Flow with Vacuum-Ultraviolet to Near-Infrared Spectroscopy," Journal of Thermophysics and Heat Transfer, vol. 30, no. 3, pp. 673-688, 2016.

[10] H. Wei, R. G. Morgan, T. J. McIntyre, A. M. Brandis and C. O. Johnston, "Experimental and Numerical Investigation of Air Radiation in Superorbital Expanding Flow," 47th AIAA Thermophysics Conference, AIAA AVIATION Forum, no. AIAA 2017-4531, 2017. 
[11] C. O. Laux, R. J. Gessmann and C. H. Kruger, "lonizational Nonequilibrium Induced by Neutral Chemistry in Air Plasmas," AIAA journal, vol. 34, no. 8, pp. 1745-1747, 1996.

[12] C. O. Laux, L. Pierrot and R. J. Gessman, "State-to-state modeling of a recombining nitrogen plasma experiment," Chemical Physics, vol. 398, pp. 46-55, 2012.

[13] A. C. Tibère-Inglesse, S. McGuire, P. Mariotto and C. O. Laux, "Validation cases for recombining nitrogen and air plasmas," Plasma Sources Science and Technology, vol. 27, no. 11, p. 115010, 2018.

[14] G. V. Candler, C. O. Laux, R. J. Gessman and C. H. Kruger, "Numerical Simulation of a Nonequilibrium Nitrogen Plasma Experiment," 28th Plasmadynamics and Lasers Conference, Fluid Dynamics and Colocated Conferences, no. AIAA 1997-2365, 1998.

[15] M. Nagulapally, D. Kolman, G. V. Candler, C. O. Laux, R. J. Gessman and C. H. Kruger, "Numerical Simulation of Nonequilibrium Nitrogen and Air Plasma Experiments," 29th AIAA, Plasmadynamics and Lasers Conference, Fluid Dynamics and Co-located Conferences, no. AIAA 1998-2665 , 1998.

[16] M. E. MacDonald, C. M. Jacobs, C. O. Laux, F. Zander and R. G. Morgan, "Measurements of air plasma/ablator interactions in an inductively coupled plasma torch," J. Thermophys. Heat Transfer, vol. 29, no. 1, pp. 12-23, 2015.

[17] C. O. Laux, "Optical diagnostics and radiative emission of air plasmas," PhD Thesis, Stanford University, 1993.

[18] C. O. Laux, T. G. Spence, C. H. Kruger and R. N. Zare, "Optical diagnostics of atmospheric pressure air plasmas," Plasma Sources Science and Technology, vol. 12, no. 2, pp. 125-138, 2003.

[19] B. J. McBride and S. Gordon, "Computer Program for Calculation of Complex Chemical Equilibrium Compositions and Applications II. User's Manual and Program Description," NASA RP-1311-P2, June 1996.

[20] S. D. McGuire, A. C. Tibère-Inglesse and C. O. Laux, "Ultraviolet Raman spectroscopy of N2 in a recombining atmospheric pressure plasma," Plasma Sources Science and Technology, vol. 26, no. 11, p. 115005, 2017.

[21] G. Candler, "The computation of weaakly ionized hypersonic flows in thermo-chemical nonequilibrium," PhD Thesis, Stanford University, 1988.

[22] R. J. Gollan, "The computational modelling of high-temperatures gas effects with application to hypersonic flows," PhD Thesis, University of Queensland, 2008.

[23] V. Casseau, R. C. Palharini, T. J. Scanlon and R. E. Brown, "A Two-Temperature Open-Source CFD Model for Hypersonic Reacting Flows, Part One: Zero-Dimensional Analysis," Aerospace, vol. 4, no. 34, 2016.

[24] R. C. Millikan and D. R. White, "Vibrational Energy Exchange between N2 and CO. The Vibrational Relaxation of," The Journal of Chemical Physics, vol. 39, no. 1, pp. 98-101, 1963.

[25] R. C. Millikan and D. R. White, "Vibrational relaxation in air," American Institute of Aeronautics and Astronautics Journal, vol. 2, no. 10, pp. 1844-1846, 1964.

[26] M. Capitelli, C. Gorse, S. Longo, N. Dyatko and K. Hassouni, "Non-Maxwell Behavior of Electron Energy Distribution Functions in Expanding Nitrogen Arcs," Journal of Thermophysics and Heat Transfer, vol. 12, no. 4, pp. 478-481, 1998.

[27] A. Plain, C. Gorse, M. Cacciatore, M. Capitelli, B. Massabieux and A. Ricard, "On the coupling between $\mathrm{Nd} 2\left(\mathrm{~B} 3 \Pi \mathrm{g}, \mathrm{v}^{\prime}\right)$ and $\mathrm{N} 2(\mathrm{X} 1 \Sigma \mathrm{g}, \mathrm{v})$ vibrational distributions in a glow discharge column in flowing N2," Journal of Physics B: Atomic and Molecular Physics, vol. 18, no. 4, pp. 843-849, 1985.

[28] A. C. Eckbreth, Laser Diagnostics for Combustion Temperature and Species, Taylor \& Francis, 1996.

[29] M. Panesi, R. L. Jaffe, D. W. Schwenke and T. E. Magin, "Rovibrational internal energy transfer and dissociation of N2(15g+)-N(4Su) system in hypersonic flows," The Journal of Chemical Physics, vol. 138, no. 4, p. 044312, 2013. 